\title{
Enfrentamento de puérperas HIV positivas relacionado ao ato de não amamentar*
}

\author{
Confronting HIV-positive mothers about the act of not breastfeeding
}

Enfrentamiento de puérperas HIV positivas al hecho de no amamantar

Meliana Gisleine de Paula ${ }^{1}$, Cátia Millene Dell'Agnolo ${ }^{2}$, Maria Dalva de Barros Carvalho ${ }^{3}$, Sandra Marisa Pelloso ${ }^{4}$

* Extraído de Dissertação de Mestrado defendida junto ao Programa de Pós-Graduação em Ciências da Saúde da Universidade Estadual de Maringá.

${ }^{1}$ Enfermeira, Mestre em Ciências da Saúde. Enfermeira do Hospital Universitário Regional de Maringá da Universidade Estadual de Maringá (HUM/UEM).

Maringá, PR, Brasil. E-mail: meliana_gp@yahoo.com.br.

${ }^{2}$ Enfermeira, Mestre em Enfermagem. Enfermeira do HUM/UEM. Maringá, PR, Brasil. E-mail: catiaagnolo@gmail.com.

${ }^{3}$ Enfermeira, Doutora em Enfermagem. Professora Associada da UEM. Maringá, PR, Brasil. E-mail: mdbcarvalho@gmail.com.

${ }^{4}$ Enfermeira, Doutora em Enfermagem. Professora Associada da UEM. Maringá, PR, Brasil. E-mail: smpelloso@gmail.com.

\section{RESUMO}

O objetivo do estudo foi conhecer os sentimentos e as dificuldades de mulheres portadoras do vírus da imunodeficiência adquirida (HIV) frente à não amamentação e à assistência oferecida. Foram entrevistadas 36 mulheres/mães portadoras do HIV com acompanhamento no ambulatório de DST/aids. Estudo qualitativo que utilizou o método do Discurso do Sujeito Coletivo, representado por meio de cinco discursos. Os resultados mais relevantes apontam que as participantes da pesquisa sofrem com a impossibilidade de não amamentar seus filhos e com a falta de um cuidado individualizado, especialmente, relativos aos problemas nas mamas. Crenças foram evidenciadas nos discursos que desmistificam o simbolismo do aleitamento, o que fortalece as puérperas para aceitar o fato de não poderem amamentar. Conclui-se que o cuidado a esse grupo específico deve privilegiar uma assistência individualizada que auxilie, especialmente, nos conflitos emocionais no processo da não amamentação, assim como nos problemas mamários.

Descritores: Síndrome de Imunodeficiência Adquirida; Aleitamento Materno; Transmissão Vertical de Doença Infecciosa; Cuidados de Enfermagem; HIV.

\section{ABSTRACT}

The objective of this study was to learn the feelings and difficulties of women with the human immunodeficiency virus (HIV) in face of not breastfeeding and the care offered to them. Thirty-six women/mothers with HIV and under follow-up at an STD/Aids outpatient clinic were interviewed. A qualitative study was conducted, using the Collective Subject Discourse method, which was represented by means of five discourses. The most relevant results show that the study participants suffer as a result of not being able to breastfeed their children and the lack of individualized care, especially regarding breast issues. The discourses evidenced beliefs that demystify the symbolism of breastfeeding, which strengthens these women to accept the fact that they cannot breastfeed. In conclusion, the care for this specific group must be individualized so as to assist them, especially, with their emotional conflicts in the non-breastfeeding process, as well as with their breast problems.

Descriptors: Acquired Immunodeficiency Syndrome; Breast Feeding; Infectious Disease Transmission, Vertical; Nursing Care; HIV.

\section{RESUMEN}

Se objetivó conocer los sentimientos y las dificultades de mujeres portadoras del virus de inmunodeficiencia adquirida (HIV) ante el no amamantamiento y la atención ofrecida. Fueron entrevistadas 36 mujeres/madres portadoras de HIV con seguimiento en ambulatorio de DST/SIDA. Estudio cualitativo, utilizando el Discurso del Sujeto Colectivo, representado mediante cinco discursos. Los resultados más relevantes expresan que las participantes de la investigación sufren ante la imposibilidad de amamantar a sus hijos y con la falta de cuidados personalizados, especialmente en lo relativo a problemas en las mamas. Las creencias fueron evidenciadas en los discursos, que desmitifican el simbolismo de la lactancia, lo cual ayuda a las puérperas a aceptar el hecho de no poder amamantar. Se concluye en que el cuidado del grupo específico debe privilegiar una atención personalizada, que colabore, particularmente, en los conflictos emocionales relativos al proceso de no amamantamiento, así como en los problemas mamarios.

Descriptores: Síndrome de Inmunodeficiencia Adquirida; Lactancia Materna; Transmisión Vertical de Enfermedad Infecciosa; Atención de Enfermería; VIH. 


\section{INTRODUÇÃO}

Desde o início da epidemia em 1980 até junho de 2012, o Brasil registrava 656.701 casos de síndrome da imunodeficiência adquirida (AIDS), com uma taxa de incidência em 2011 de 20,2 casos por 100 mil habitantes. Com exceção da Região Sudeste, todas as demais registraram um aumento, saltando de 27,1 para 30,9 casos por 100 mil habitantes na região Sul do Brasil( ${ }^{(1)}$.

A faixa etária mais incidente é a de 25 a 49 anos de idade, para ambos os sexos. A razão de sexos (número de casos em homens dividido pelo número de casos em mulheres) que em 1989 era de seis homens para cada mulher, em 22 anos modificou para 1,7 homem para cada mulher. As mulheres estão se contaminando mais e precocemente em relação aos homens ${ }^{(1)}$.

O crescimento da epidemia da AIDS nos últimos anos, em especial entre as mulheres, tem chamado a atenção para um novo desafio relacionado ao controle da transmissão vertical (TV) do $\mathrm{HIV}^{(2)}$, devido a um aumento da infecção pelo HIV em gestantes ${ }^{(3)}$.

Mundialmente, a transmissão vertical (de mãe para filho) representa a principal causa de infecções pediátricas por HIV (mais de $90 \%$ dos casos) ${ }^{(4)}$. Em países como África do Sul, onde a prevalência de HIV é elevada, há uma escassez de dados sobre a efetividade de programas nacionais de prevenção da transmissão vertical ${ }^{(5)}$.

Atualmente, eliminar a transmissão vertical é uma das prioridades mundiais no campo da saúde pública ${ }^{(6)}$.

Nos Estados Unidos, teste de rotina pré-natal para HIV, teste rápido para HIV durante o parto, terapia antirretroviral (ARV) materna, infantil e alimentação com fórmula, ou seja, ausência de aleitamento materno, têm sido creditados como fatores responsáveis para a redução na TV, embora o autor da pesquisa especifique que o país tem sofrido críticas relacionadas à não amamentação materna ${ }^{(7)}$. O risco de TV do HIV é de cerca de $0,1 \%$, com a supressão viral durante o parto, no momento pós-parto, profilaxia da criança e ausência de aleitamento materno ${ }^{(8)}$.

No Brasil entre os anos de 2003 a 2012 foi verificado um aumento de $26,3 \%$ na taxa de detecção em gestantes. No ano de 2012 a taxa de detecção de HIV em gestantes apresentou 2,4 casos por 1.000 nascidos vivos. A região Sul foi a única que apresentou detecção superior aos dados nacionais, com coeficiente de 5,8 por 1.000 nascidos vivos ${ }^{(3)}$.

O contágio da mãe para o filho pode acontecer na gestação, durante o parto ou na amamentação( ${ }^{(9)}$. É possível evitar a TV em até $99 \%$, caso o diagnóstico seja rápido e a gestante receba tratamento com medicamentos antirretrovirais $^{(9)}$.
A transmissão do HIV pelo aleitamento materno é discutida desde 1991. Não existem questionamentos sobre a presença do vírus no leite humano e nem sobre o seu potencial infectante, responsável por $14 \%$ dos casos de TV do HIV-1, em gestantes com infecção crônica. O fato de a mãe utilizar ARV não controla a eliminação do HIV-1 pelo leite ${ }^{(2,10)}$. A exclusão da amamentação em mulheres infectadas reduz em até $20 \%$ as chances da contaminação da criança ${ }^{(11)}$. Em caso de amamentação em mães sem uso ARV, atribui-se números que vão de 129.000 a 194.000 infecções por HIV em todo o mundo ${ }^{(4,12)}$. Um estudo realizado na África, visando analisar o leite materno, não mostrou nenhuma correlação entre marcadores imunológicos, evolução da doença e a composição do leite materno, ou seja seria ainda a melhor indicação para a alimentação das crianças ${ }^{(13)}$.

Vários trabalhos descrevem que mulheres infectadas pelo HIV são desencorajadas a amamentar devido ao risco de TV do HIV aos seus filhos por meio do leite materno ${ }^{(14-}$ 18).

Nos Estados Unidos, embora a não amamentação tem sido uma recomendação padrão nos últimos 30 anos visando evitar a TV do HIV, muitas mulheres têm optado por amamentar seus filhos ${ }^{(7)}$. Alguns autores mencionam o conflito das mulheres por não poderem proporcionar a seus filhos o leite materno, associado a outros problemas, como sofrimento psicológico problemas mamários, problemas culturais e sociais ${ }^{(11,19)}$.

Diante desta problemática, este estudo objetivou conhecer a vivência das mulheres que vivem com HIV frente a não amamentação e os aspectos referentes à assistência oferecida neste período.

\section{MÉTODOS}

Trata-se de estudo qualitativo, tendo como referencial metodológico o do discurso do sujeito coletivo (DSC).

O DSC é uma forma de fazer "um sujeito" falar pelo eu em representação de uma coletividade. Este método consiste na análise do material verbal coletado, extraindose as figuras metodológicas de cada relato, que são as Expressões-Chave (ECH), identificadas por trechos dos depoimentos que revelam a essência do depoimento ou parte dele; as Idéias Centrais (IC), que sintetizam em forma de uma expressão linguística o sentido dos discursos das $\mathrm{ECH}$ e a Ancoragem (AC) que inspira uma teoria de representação social que aparece nos depoimentos, como crença professada pelo autor do discurso de forma mais genérica. Assim, o agrupamento das $\mathrm{ECH}$ que originaram as IC ou AC origina um ou vários DSC, sendo estas as quatro figuras metodológicas que 
compõem o método. O DSC construído e redigido na primeira pessoa do singular, passa a representar a coletividade $^{(20)}$.

A ideia central é o nome ou expressão linguística que revela e descreve, de maneira sintética e precisa, o sentido presente nos depoimentos. Descreve o sentido usando as palavras do entrevistado, não constituindo interpretação. As ideias centrais são elaboradas pelo pesquisador diante do discurso do entrevistado utilizando a fala que as indicam "fortemente". É preciso um critério que justifique a ideia central. A partir daí, o pesquisador faz uma síntese daquilo que foi justificado. As ideias centrais servem para agrupar o discurso, podendo haver numa mesma fala mais que uma ideia central; todas elas devem ser consideradas separadamente e trabalhadas no processo de categorização(21).

O processo final da técnica do DSC é a elaboração da síntese, ou seja, trata de fazer a reunião: utilizando discurso único redigido na primeira pessoa do singular, expressões-chave que apresentam ideias centrais ou ancoragens semelhantes ${ }^{(21)}$.

À medida que os DSC vão sendo construídos, compõem-se o sistema de interpretação da realidade pelos participantes, as relações estabelecidas por eles no contexto social, bem como vão se colocando em relevo seus comportamentos e práticas ${ }^{(21)}$.

Nesse processo de construção dos DSC, os cenários sociais se apresentam enriquecidos de Representações Sociais, nos quais as práticas se mostram organizadas. É através desse espelho coletivo que o pesquisador tem às suas mãos uma riqueza de informações que Ihe auxiliará na condução do plano de cuidado à saúde ${ }^{(21)}$.

O estudo foi realizado no ambulatório de DST/AIDS da cidade de Maringá, Paraná, Brasil, que atende a população de 30 municípios da 15a Regional de Saúde do Estado, no período de novembro de 2009 a maio de 2010.
No período da pesquisa 78 mulheres foram notificadas como gestantes vivendo com HIV, e convidadas a participar do estudo. A amostra foi composta de 36 gestantes que compareceram ao ambulatório no período estudado e aceitaram participar da pesquisa.

Para a coleta dos dados utilizou-se a seguinte pergunta orientadora: "Falando de amamentação, qual o seu sentimento de não poder amamentar e como você foi orientada?". Foi realizada uma entrevista, necessária para que o indivíduo expresse livremente seu pensamento e a coleta dos discursos dos sujeitos possam representar a coletividade $^{(20)}$. As entrevistas foram gravadas em gravador digital, transcritas na íntegra e após sua utilização foram inutilizadas. Para manter o anonimato as participantes foram identificadas com a letra $M$ seguida do numero de ordem da entrevista. Todas as participantes assinaram o termo de consentimento livre e esclarecido após receberem informações sobre a pesquisa no início das entrevistas e terem suas dúvidas esclarecidas.

A análise e organização dos dados foi realizada utilizando o programa QualiQuantiSoft ${ }^{\circledR}$ e o Discursos do Sujeito Coletivo proposto por Lefévre e Lefévre ${ }^{(20)}$. O projeto de pesquisa foi aprovado pelo Comitê de Ética e Pesquisa da Universidade Estadual de Maringá sob o parecer 537/2009.

\section{RESULTADOS}

\section{Caracterização dos sujeitos}

Das 36 mulheres, a maior parte encontrava-se na faixa etária de 16 a 41 anos com uma média de idade de 28 anos. Eram na maioria mulheres casadas ou com parceiro fixo, com escolaridade ensino fundamental completo, baixa renda, sem atividade remunerada, de cor parda e professavam alguma religião.

Quadro 1: Compreendendo a proibição do ato de amamentar. Maringá, PR, Brasil, 2010.

\begin{tabular}{|r|}
\hline Tema - Compreendendo a proibição do ato de amamentar \\
\hline (M03;M04;M11;M16;M17;M18;M20;M23;M26;M34). \\
\hline Discurso do Sujeito Coletivo \\
pu olhava pra ela e me sentia feliz por tê-la, pensava assim: tem tantas mães aí que tem condições e não amamentam! Eu não \\
maneira dela sobreviver eu agradeci. Não poder amamentar, não me deixou grilada. E eu não tive leite. E até hoje, nunca senti \\
falta. Eu pensava naquela vontade que eu tinha, mas não, eu não dei, não ia fazer mal pra ela. Às vezes eu pensava que ia estar \\
fazendo o bem, mas fazendo o bem eu poderia tá fazendo o mal também né? Fiquei triste né? Mas como era para um bem do \\
neném, aí eu não me importei muito não! Eu tive o privilégio da minha filha ter saúde, e isso já me basta, é o mais importante. Se \\
você amamenta é perigoso a criança ter a doença. A gente fica meio chateada, mas tem que pôr na cabeça, e eu, não sofri com isso \\
não, isso é tudo uma questão de consciência, tem que trabalhar seu psicológico. Se você sabe que não pode não pode, vai sofrer \\
pra se prejudicar?
\end{tabular}


Quadro 2: Desfazendo o simbolismo maternal da amamentação e aceitando a realidade. Maringá, PR, Brasil, 2010.

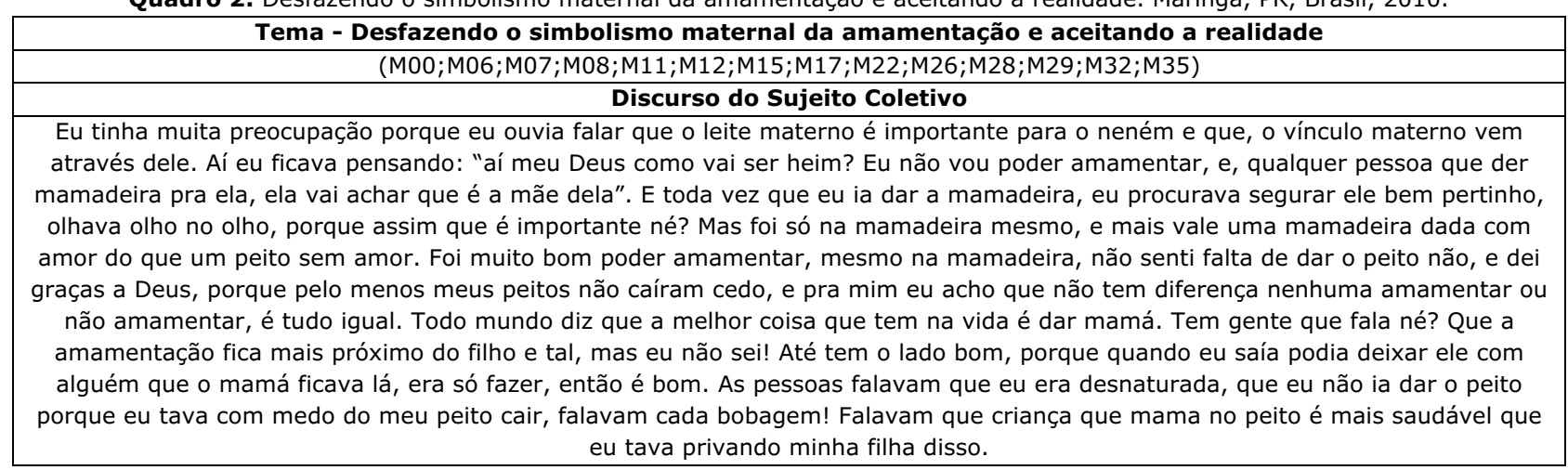

Quadro 3: Sofrimento por já ter amamentado. Maringá, PR, Brasil, 2010.

Tema - Sofrimento por já ter amamentado (M00; M21;M24;M30)

\section{Discurso do Sujeito Coletivo}

Eu amamentei os meus outros filhos e não poder amamentar este me dói. Então, não amamentar é uma situação difícil, ver seu filho sair de dentro de você ali, e, não poder dar o seu leite pra ele? E eu tinha leite! Tenho até hoje! É uma situação bem triste, é como se eu não fosse uma mãe completa. Porque pra minha primeira filha eu dei e pra ele não, então pra mim fica como se eu, não que eu tivesse menosprezando ele, mas é uma situação esquisita em relação a outra, tendo um leite muito bom, o leite do peito, e não pode dar. Pra outra eu já dei pouco, porque eu não tinha né? E essa nem que fosse pra eu dar uma semana né? Eu até tive depressão pós-parto por causa disso, porque eu não conseguia admitir. Ter amamentado a outra por 11 meses, e quando eu olhei aquela coisinha ali e eu explodindo de leite foi me dando uma revolta! A minha filha precisando daquilo, eu tendo sobrando, e não podendo dar. Isso foi uma coisa que mexeu muito comigo, eu cheguei ir pra psicóloga pra trabalhar um pouco a minha cabeça porque eu não conseguia entender.

Quadro 4: Sofrendo com a representação sócio-afetiva da amamentação. Maringá, PR, Brasil, 2010.

\begin{tabular}{|c|}
\hline Tema - Sofrendo com a representação sócio-afetivo da amamentação \\
\hline (M2;M3;M4;M6;M9;M10;M13;M14;M17;M18;M21;M24;M27;M29;M30;M32;M34;) \\
\hline Discurso do Sujeito Coletivo \\
\hline $\begin{array}{l}\text { Nem levar ele no postinho pra fazer consulta eu levo, quem leva é meu marido, só pra eu não ficar vendo as outras mães dando de } \\
\text { mamá. Aí eu não aguento! Ter que ficar vendo todo mundo amamentando, e só eu que não? Ai, eu saía de perto, nem queria ver. } \\
\text { As outras crianças choravam e as mães davam o peito na horinha, a minha tinha que esperar. Eu não aguentava ver aquilo, aí pedi } \\
\text { para mudar de quarto, e me colocaram junto com as pessoas que tinham o mesmo problema que eu. Confesso que fiquei triste sim, } \\
\text { vendo aquelas mães amamentarem e eu não podia. E ainda, todo mundo perguntava por que eu não podia? Eu tinha que mentir, } \\
\text { falava que eu não tinha leite, que meu leite não desceu, tinha que ficar inventando estória, cada hora falando uma coisa. E eu tinha } \\
\text { tanto leite! Aí falava que tinha problema no sangue e não podia amamentar, eu sofria demais com isso lá. Passei minha dieta } \\
\text { mentindo, cada hora mentindo e elas me perguntando, caí na depressão, eu ficava tão nervosa de ter que ficar mentindo! Até dizia } \\
\text { que eu não gostava de amamentar. "Não quero! Não gosto!". E as pessoas me criticavam por eu não amamentar! E você ali, com } \\
\text { seu leite perdendo, e não poder amamentar, é difícil! É estranho. Dá dó da criança. Sei lá, só a gente passando mesmo pra saber, é } \\
\text { complicado! É como se faltasse um pedaço, falta uma parte da gente enquanto mãe, uma obrigação que você tem e não pode fazer } \\
\text { pelo seu filho, como se fosse uma punição pra ele, já imaginou? ter um filho e não amamentar! E assim, mesmo você não } \\
\text { amamentando, o bebê tem aquele instinto de mamar. Eles ficam fuçando na gente, vêem com a cabecinha se aninhando, e a gente } \\
\text { fica vendo aquilo e fica super triste, sabendo que a gente põe filho no mundo e não pode amamentar, é de ficar bem triste. }\end{array}$ \\
\hline
\end{tabular}

Quadro 5: Cuidados com as mamas. Maringá, PR, Brasil, 2010.

\begin{tabular}{|c|}
\hline Tema - Cuidados com as mamas \\
\hline (M00;M01;M02;M03;M04;M05;M06;M07;M08;M09;M10;M11;M17;M18;M21;M24;M25;M26;M27;M28;M31;M32;M33;M35) \\
\hline Discurso do Sujeito Coletivo \\
\hline $\begin{array}{l}\text { Fui orientada para não amamentar. Eles me ofereceram o leite durante os seis meses. Eu tinha bastante leite. Meus peitos ficaram } \\
\text { cheios, vazavam noite e dia, era triste não poder amamentar, eles pegavam fogo de tão cheio que ficou. No hospital, o médico disse } \\
\text { que se eu desse o peito, o bebê podia adquirir o vírus, aí me deram uma injeção e o leite não desceu, saí do hospital com as mamas } \\
\text { toda enfaixada para não estimular, e fui pra casa com aquilo, mas chegando em casa eu tirei a faixa não aguentava aquilo me } \\
\text { apertando, me sentia sufocada. Tinha muito leite! Tinha não, ainda tenho, chega a tarde meus peitos ficam todos doloridos, dói! } \\
\text { Pediram pra eu apertar bem as mamas e fazer compressa com gelo. Eu colocava aquelas bolsas de gelo no peito pra secar, mas em } \\
\text { casa meus peitos encheram de leite ficou tudo duro assim, eu não enfaixei, porque a faixa me dava alergia. Na gravidez do meu } \\
\text { primeiro filho não fizeram nada, mas desta sim. Em São Paulo, eles tem um banco de leite que pasteuriza para estes casos, só que } \\
\text { eu já tava com tanto medo que eu não quis. Não me deram a medicação, eu sabia que eu ia tomar a Carbergolina, mas tava em } \\
\text { falta, aí eles fizeram muita compressa de gelo, enfaixaram mas não resolveu, aquilo foi empedrando, doendo, foi horrível, cheguei } \\
\text { ao ponto quase de desmaiar de tanta dor que eu sentia, aí tive que ser internada pra tratar. O médico me orientou tomar banho } \\
\text { com água bem quente e enfaixar, mas não adiantou. Passei bem mal também com os comprimidos. }\end{array}$ \\
\hline
\end{tabular}

\section{DISCUSSÃo}

Mulheres com infecção pelo HIV na fase avançada da doença já experienciam modificações no seu cotidiano pelo seu diagnóstico, como restrições de atividades no lar, saída do emprego, além das perdas relacionadas ao comprometimento físico, o que gera/acentua sentimento de angústia/depressão. Tudo isso acompanhado de uma sensação de inutilidade pelo fato de não conseguirem desempenhar algumas atividades diárias corriqueiras ${ }^{(22)}$. Entender como elas vivenciam uma gravidez neste 
contexto e, principalmente a inibição da lactação nestas mães, torna-se imprescindível aos profissionais da área da saúde.

Nos últimos anos, os estudos têm priorizado a TV do HIV, composição do leite materno em mães com infecção pelo HIV e terapia ARV no pré-natal, parto e pós-parto, assuntos de extrema importância e que têm contribuído para a sua redução, a nível mundial.

Porém, pesquisas voltadas aos sentimentos das mães relacionados ao fato de não amamentar são pouco evidentes na literatura, tanto nacional quanto internacional.

\section{Discurso do sujeito coletivo}

O DSC representado pelo tema descrito no Quadro 1, retrata a compreensão que as mulheres tiveram em relação ao impedimento do ato de amamentar, tendo como a IC uma maneira de ter a criança saudável. Assim, pode-se afirmar que as intervenções mais efetivas para que este fato fosse compreendido, foram às orientações que ocorreram no pré-natal, e resultados insatisfatórios na inibição da amamentação foram vistos quando não ocorre esta conduta ${ }^{(23)}$.

As ações maternais que envolvem o aleitamento materno são determinadas por uma visão pessoal de experiências, assim a percepção e a significação do ato de amamentar são influenciadas por questões sociais, culturais e familiares ${ }^{(24)}$.

A crença do simbolismo maternal é visto de certa forma como uma desconstrução, e essas mulheres passaram a conviver com a possibilidade de amamentar seus filhos através de mamadeiras, numa experiência aceitável e reconstroem através de expressões únicas e positivas, um novo paradigma de cuidado com amor e atenção, mesmo com a oferta da mamadeira.

Essa vivência se contrapõe à encontrada em estudo realizado em São Paulo, Brasil, onde o ato de não amamentar foi considerado penoso e emocionalmente desgastante ${ }^{(24)}$. Por outro lado, para as mulheres do presente estudo que já tinham vivido a experiência da amamentação, não poder repetir o ato foi sentido como negativo.

No Quadro 3, o discurso coletivo das mulheres descreve a não amamentação como uma negação do filho, um sofrimento psíquico e moral, fortalecendo a percepção de impotência e revolta, aparecendo como IC o fato de ter amamentado o outro filho, e este eu não posso, isto é muito difícil.

Para a mulher que já experienciou a amamentação, torna-se mais difícil aceitar que para este filho ela não pode expressar seu ato de amor, aliado ao sentimento de impotência, de culpa e de incompetência.

Pode-se observar que a não-amamentação para essas mulheres foi de certa forma atestado de perdão, a possibilidade de dar seguimento à vida, forma de se sentirem parte ou totalmente afastadas do processo de decisão sobre a alimentação do filho ${ }^{(24)}$.

Além da amamentação, outras questões complexas do vivenciar uma gestação sendo portadoras de infecção por HIV, não são discutidas e relatadas durante o prénatal.

Aspecto importante a ser destacado neste discurso foi o sofrimento de ver outras mulheres amamentando e não poder fazer o mesmo (Quadro 4).

Vivenciar a maternidade sem o direito de amamentar e presenciar a amamentação de outras pessoas gera nas mulheres sentimento de tristeza e angústias.

A mulher não conta sobre seu diagnóstico, e tem medo de que não amamentar revele sua situação sorológica para os outros. Assim se omite aos questionamentos, ou já se prepara anteriormente para uma resposta que justifica o fato de não estar amamentando ${ }^{(25)}$.

Neste estudo, a cobrança social colocou as mulheres em situação constrangedora, fazendo-as buscar desculpas socialmente aceitas para justificar a nãoamamentação(24).

$\mathrm{O}$ ato de não amamentar gerou neste grupo de mulheres sentimentos de culpa e tristeza, sendo necessário suporte emocional e técnico, não só para as dores das mamas como no alívio da alma ${ }^{(24-25)}$.

Neste sentido, atitudes como mantê-las em quartos privativos para protegê-las dos interrogatórios inevitáveis por outras puérperas, e da tortura de presenciar o "ato de amor" de outras mães, assim como prepará-las para esta possibilidade, também são necessidades assistenciais que os profissionais de saúde devem se atentar.

É notório o sofrimento que as mulheres passam em relação a cuidados relacionados com as mamas ingurgitadas pela impossibilidade de não amamentação (Quadro 5). Foi possível observar no discurso atitudes que refletem a falta de conhecimento das mulheres na compreensão ou na realização dos cuidados corretos.

Estudo realizado com puérperas com infecção pelo HIV de Fortaleza, Brasil, foi revelado que o uso de fármacos e o enfaixamento das mamas nestas mulheres no puerpério ocorreram de forma limitada, e estas realizaram práticas empíricas para o alívio de seu desconforto $^{(11)}$. O enfaixamento das mamas, mesmo que indicado, é vista por algumas mulheres como exposição 
da sua figura, o que faz com que se sintam excluídas e discriminadas, considerando esta uma ação altamente punitiva $^{(24)}$.

Neste estudo, a indicação do enfaixamento representou também um incômodo, onde as mulheres se sentiam sufocadas, com alergias e desvalorizando tal prática. O modo de evitar estas situações seria o engajamento ético do profissional nos serviços de saúde, onde muitas mulheres com infecção pelo HIV fazem o prénatal, o parto e o puerpério sem receber a devida atenção que necessitam para as peculiaridades que as diferem de outras mães ${ }^{(19,24)}$.

Promover a saúde não está centrado apenas na prevenção da transmissão vertical, mas também no desenvolvimento do equilíbrio físico, social e emocional destas mulheres e crianças.

\section{CONCLUSÃO}

Atualmente, o assunto amamentação entre mães HIV positivas ainda é bastante controverso, como apontam os resultados do estudo. Alguns países estimulam e orientam a sua supressão, enquanto que outros, por questões financeiras ou indisponibilidade de outras formas de alimentação priorizam e incentivam a sua continuidade nestes casos. Terapia ARV no pré-natal, parto e pós parto, bem como profilaxia da criança após o nascimento são realizados em alguns países que orientam as mães a iniciar e prosseguir com o aleitamento materno.

\section{REFERÊNCIAS}

1. Departamento de DST, Aids e Hepatites Virais. Ministério da Saúde. Aids no Brasil. Brasília (Brasil): Ministério da Saúde, 2012.

2. Ministério da Saúde. Secretaria de Vigilância em Saúde. Departamento de DST, AIDS e Hepatites Virais. Recomendações para profilaxia da transmissão vertical do HIV e terapia antiretroviral em gestantes. Brasília (Brasil): Ministério da Saúde, 2010.

3. Ministério da Saúde. Departamento de DST, AIDS e Hepatites Virais. Protocolo clínico e diretrizes terapêuticas para manejo da infecção pelo HIV em crianças e adolescentes [Internet]. 2014

[acesso em: 25 set 2014]; Disponível em: http://www.aids.gov.br/pcdt/pediatrico/1.

4. Muluye D, Woldeyohannes D, Gizachew M, Tiruneh M. Infant feeding practice and associated factors of HIV positive mothers attending prevention of mother to child transmission and antirretroviral theraphy clinics in Gondar Town health institutions, Northwest Ethiopia. BMC Public Health.

2012;12:240.

5. Goga AE, Dinh TH, Jackson DJ, Lombard C, Delaney KP, Puren $A$, et al. First population-level effectiveness evaluation of a national programme to prevent HIV transmission from mother to child, South Africa PMTCT Evaluation (SAPMCTE). J Epidemiol Community Health. 2014;0:1-9.

6. United Nations. The Millennium Develpment Goals Report [Internet]. 2012 [acesso em: 22 nov 2014]; Disponível em: http://www.un.org/millenniumgoals/pdf/MDG\%20Report\%20201 2.pdf.
Neste estudo, que reflete a realidade de um município do Sul do Brasil, os resultados apontam os sentimentos e as dificuldades destas mães portadoras do HIV frente a não amamentação, possibilitando aos profissionais de saúde que prestam atendimento à mulheres/mães com infecção pelo HIV tanto na gestação, parto e puerpério, conhecer às questões que permeiam a inibição da lactação, as quais vão, muito além de questões fisiológicas de TV, demonstrando as questões emocionais e físicas pelas quais estas mães são expostas. O papel do enfermeiro no cuidado às mães com infecções pelo HIV precisa incorporar a reflexão sobre a qualidade da assistência voltada a estas mulheres, no sentido de garantir cuidado humanizado, efetivo e individualizado, focado nos direitos humanos e não apenas em conhecimentos de questões técnicas.

A assistência individualizada e humanizada nos serviços de saúde pode evitar danos emocionais desnecessários a estas mulheres na tocante a interrupção não desejável da amamentação.

Diante da problemática levantada, considera-se a necessidade de trabalhos futuros que verifiquem a transmissão do vírus do HIV através do leite materno após o emprego dos novos tratamentos com anti-retrovirais, bem como condutas mais eficazes na inibição da lactação. É importante salientar a atuação dos bancos de leites humanos na garantia e na possibilidade de oferta do leite materno humano das mães a estas crianças.

7. Levison J, Weber S, Cohan D. Breastfeeding and HIV-Infected Women in the United States: Harm Reduction Counseling Strategies. Clin Infect Dis. 2014;59(2):304-9.

8. Townsend $\mathrm{Cl}$, Cortin-Borja $\mathrm{M}$, Peckham CS, de Ruiter A, Lyall $\mathrm{H}$, Tookey PA. Low rates of mother-to-child transmission of HIV following effective pregnancy interventions in the United Kingdom and Ireland, 2000-2006. AIDS. 2008;22(8):973-81. 9. Departamento de DST, Aids e Hepatites Virais. Ministério da Saúde. É possível evitar em mais de $99 \%$ a transmissão do vírus da gestante para o bebê, a transmissão vertical, caso o diagnóstico.... Brasília (Brasil): Ministério da Saúde, 2005. 10. Silva MJM, Mendes WS, Gama MEAG, Chein MBC, Veras DS. Perfil clínico-laboratorial de crianças vivendo com HIV/AIDS por transmissão vertical em uma cidade do Nordeste brasileiro. Rev. Soc. Bras. Med. Trop. 2010;43(1):32-35.

11. Machado MMT, Braga MQC, Galvão MTG. Problemas com a mama puerperal revelados por mães soropositivas. Rev. Esc. Enferm. USP. 2010;44(1):120-125.

12. Young SL, Mbuya MN, Chantry CJ, Geubbels EP, IsraelBallard K, Cohan D, et al. Current knowledge and future research on infant feeding in the contexto of HIV: basic, clinical, behavioral, and programmatic perspectives. Adv Nutr.

$2011 ; 2(3): 225-243$.

13. Van den Heever W, de Wet G, Hattingh M. Abstracts of the HIV Drug Theraphy Glasgow Congress 2014. Journal of the International AIDS Society 2014;17(Suppl 3):19702.

14. American College of Obstetricians and Gynecologists Committee Opinion. Breastfeeding: maternal and infant aspects. Number 361 [Internet]. 2007 [acesso em: 22 nov 2014]; 
Disponível em: http://www.acog.org/-/media/CommitteeOpinions/Committee-on-Health-Care-for-UnderservedWomen/co361.pdf?dmc=1\&ts=20141123T1356338023.

15. Panel on Treatment of HIV-Infected Pregnant Women and Prevention of Perinatal Transmission. Recommendations for use of antiretroviral drugs in pregnant HIV-1-infected women for maternal health and interventions to reduce perinatal HIV transmission in the United States [Internet]. 2012 [acesso em: 22 nov 2014]; Disponível em:

http://aidsinfo.nih.gov/contentfiles/lvguidelines/perinatalgl.pdf. 16. Whitmore S, Taylor A, Espinoza L, Shouse RL, Lampe M, Nesheim S. Correlates of mother-to-child transmission of HIV in the United States and Puerto Rico. Pediatrics 2012;129:1-8.

17. American Academy of Pediatrics. Policy statement. Infant feeding and transmission of human immunodeficiency virus in the United States. Pediatrics 2013; 131:391-6.

18. American Academy of Pediatrics. Policy statement. Breastfeeding and the use of human milk. Pediatrics 2012;129:e827-41.

19. Sant'anna ACC, Seidl EMF, Galinkin AL. Mulheres, soropositividade e escolhas reprodutivas. Estud. psicol. 2008;25(1):101-109.

20. Lefèvre $F$, Lefèvre AMC. O discurso do sujeito coletivo: um enfoque em pesquisa qualitativa (desdobramentos). Caxias do Sul: EDUCS; 2003.

21. Duarte SJH, Mamede MV, Andrade SMO. Opções teóricometodológicas em pesquisas qualitativas : Representações Sociais e Discurso do Sujeito Coletivo. Saúde Soc São Paulo. $2009 ; 18(4): 620-626$.

22. Carvalho CML, Galvão MTG, Silva RM. Alterações na vida de mulheres com Síndrome da Imunodeficiência Adquirida em face da doença. Acta Paul Enferm. 2010;23(1):94-100.

23. Queiroz PS, Oliveira LRB, Martins CA. Elementos que interferem na amamentação exclusiva: percepção de nutrizes. Revista de Salud Pública. 2009; XIII(2):6-14.

24. Moreno CCGS, Rea MF, Filipe EV. Mães HIV positivo e a nãoamamentação. Rev. bras. saude mater. infant. 2006;6(2):199208.

25. Padoin SMM, Souza IEO, Paula CC. Cotidianidade da mulher que tem HIV/aids: modo de ser diante da (im)possibilidade de amamentar. Rev. gauch. enferm. 2010;31(1):77-83.

Artigo recebido em 01/05/2013.

Aprovado para publicação em 10/09/2014.

Artigo publicado em 31/03/2015. 